\title{
133. PLANTAS MEDICINALES ESPAÑOLAS: JASONIA GLUTINOSA (L.) DC. (ASTERACEAE) (TÉ DE ROCA).
}

Luz María MUÑOZ CENTENO

Spanish medicinal plants. Jasonia glutinosa (L) DC. (Asteraceae) (Rock's tea).

Palabras clave. Plantas medicinales, té de roca, Jasonia glutinosa (L.) DC.

Key words. Medicinal plants, rock's tea, Jasonia glutinosa (L.) DC.

El presente trabajo se enmarca dentro de una de las líneas de investigación que se están llevando a cabo en el Departamento de Botánica (Facultad de Farmacia) de la Universidad de Salamanca y tiene como fin contribuir al mejor conocimiento de las especies medicinales de España. Dada la importancia que han adquirido las plantas medicinales y su creciente consumo, un estudio detallado de cada especie puede evitar posibles confusiones o adulteraciones y garantizar la utilización adecuada de las mismas.

Como material se han empleado varios ejemplares frescos de Jasonia glutinosa (L) DC. recolectados en el valle de Tabladillo (SG), 30TVL3076, 07.VIII.1996, Muñoz (SA 102472), material seco comercializado en trociscos y pliegos del herbario SALA.

El estudio morfológico se ha realizado con la ayuda de microscopios estereoscópicos de las marcas Nikon y Zeiss y un fotomicroscopio óptico Nikon Optiphot, utilizando como apoyo bibliográfico, entre otros Bolós et al. (1995), Coste (1904), Font Quer (1978), Paris et al. (1971), Tutin et al. (1976).

Para el examen anatómico-microscópico de cada uno de los órganos, se realizaron cortes de $12 \mu \mathrm{m}$ de espesor con un microtomo tipo Minot, marca Leica, previa fijación e inclusión en parafina, que se tiñeron con Fasga (Tolivia et al. 1987).

Jasonia glutinosa (L) DC. es una planta de la familia de las Asteraceae (Compositae) muy utilizada en Aragón pero poco estudiada por los autores clásicos. En el siglo XVI Micó, médico botánico catalán, la herborizó en Montserrat y la remitió a Jacques Dalechamps que la publicó en su "Historia generalis plantarum". En 1763, Linné la dio a conocer con el nombre de Erigeron glutinosum cuyo nombre específico conserva actualmente.

El nombre genérico, Jasonia, puede proceder de la palabra griega Iáson, que significa Jasón, nombre del hijo de los reyes de Tesalia y jefe de los Argonautas; el nombre específico, glutinosa, procede del latín glutinosus, que significa pegajoso, por su tacto viscoso.

\section{Nombre cientifíco}

Jasonia glutinosa (L.) DC. Prodr. 5: 476 (1836) (Chiliadenus glutinosus (L.) Fourr. Ann. Soc. Linn. Lyon. N. S. XVII (1869) 93; Jasonia saxatilis (Lamk.) Guss. Fl. Sic. Syn. II, 452).

Iconografía: Font Quer (1978): 790; Fiori et al. (1970): fig. 3.571; Valdés et al. (1987) 3: 21.

\section{Nombres vulgares}

Cast.: té de roca, té de Aragón, té de Gratal, té de peña, té de ralla, té.

Cat.: té de roca, te roquer, àrnica.

Eus.: harkaitzetako te. 

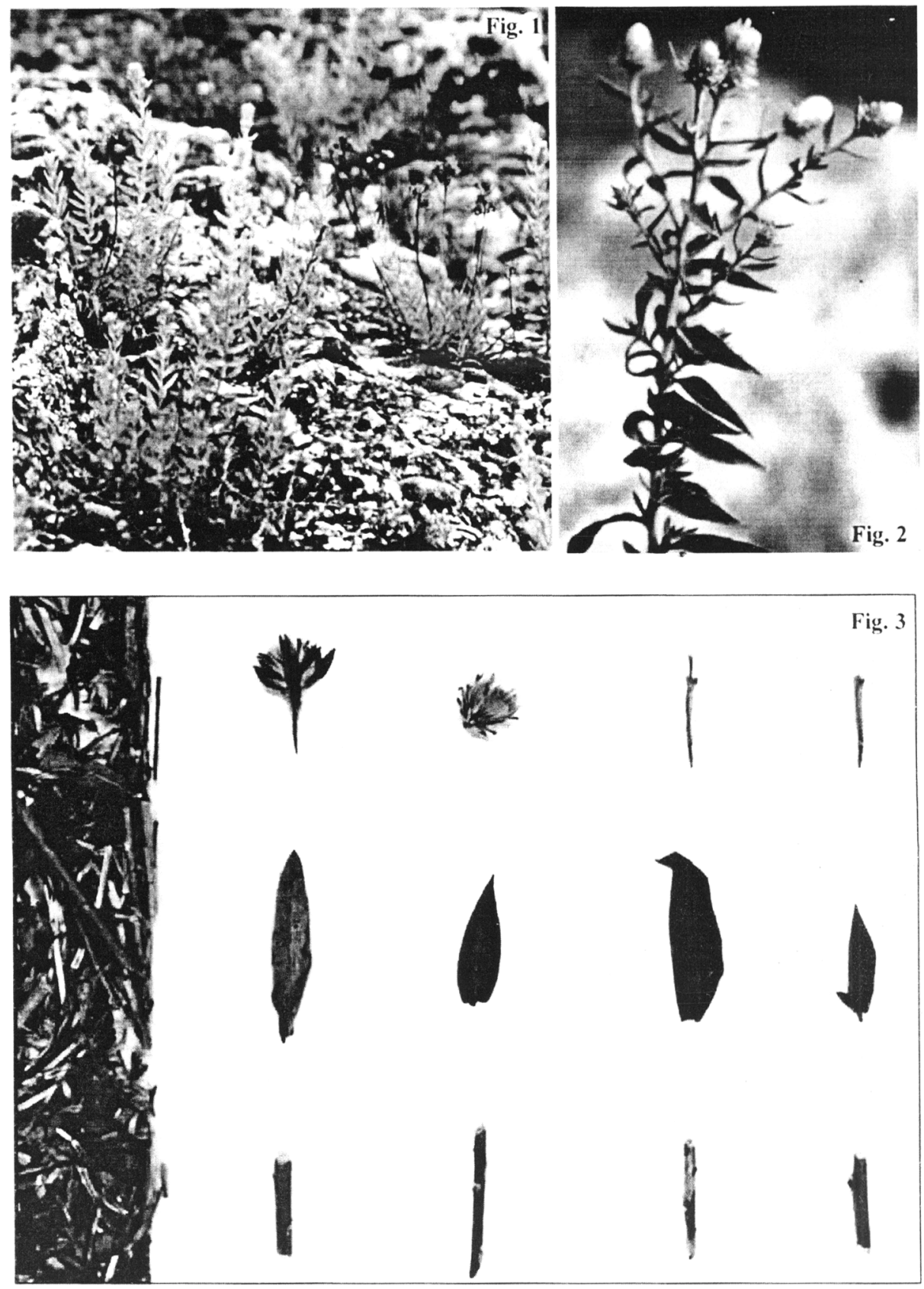

Figuras 1 a 3. Fig. 1 y 2: Jasonia glutinosa (L.) DC. Fig. 3: Órganos oficinales. Oficinal organs. 
Gal.: té de Aragón.

Fr.: thé vert.

Ing.: rock's tea.

(Pamplona, 1999)

\section{Descripción de la planta}

Planta perenne con numerosos tricomas, unos glandulares cortos, y otros tectores largos y flexuosos. El tallo es de 10-45 cm, simple o ramificado. Las hojas de 1-2,5(3)x0,2-0,5(0,6) $\mathrm{cm}$, son lanceoladas, agudas, erecto-patentes, sésiles. Los capítulos están reunidos en inflorescencias corimbosas o cimosopaniculadas y a veces solitarios. El involucro mide $6 \mathrm{~mm}$ aproximadamente y tiene brácteas en varias filas; las externas son herbáceas, glandulares y mucho más cortas que las internas; las internas son escariosas, ciliadas y sin glándulas. El receptáculo es plano o ligeramente convexo, sin brácteas interflorales. Las flores tubulosas son de color amarillo, no tiene flores liguladas. Las cipselas son vellosas y glandulares en el ápice; los pelos del vilano están dispuestos en dos filas, los externos cortos y los internos largos, denticulados y de color pardo-rojizo. Florece desde julio hasta agosto (figs. 1 y 2).

\section{Ecología y corología}

Hemicriptófito que crece en fisuras de roquedos y acantilados calizos soleados, generalmente a menos de $1.300 \mathrm{~m}$ aunque, excepcionalmente, puede alcanzar los $1.800 \mathrm{~m}$ (Pirineo central). Aparece en comunidades del orden Asplenietalia glandulosi Br. Bl. In Meier et Br. B1. 1934.

Se distribuye por la zona mediterránea occidental: España, sur de Francia, Malta, Sicilia y Norte de Africa. En España se distribuye por las comarcas pirenaicas, prepirenaicas, parte calcárea de Sierra Nevada, este peninsular, algún punto del centro peninsular y Mallorca (fig. 10), (Bolós et al. l.c.; Tutin et al. l.c.).

\section{Cultivo}

La droga procede de plantas silvestres, no suele cultivarse.

\section{Recolección}

La recolección debe realizarse antes de que se abran los capítulos, cortando las sumidades floridas por encima de su base y dejando la parte inferior de la planta para que pueda renovarse al año siguiente. Se utiliza recién cogida o desecada, en este caso deberá conservarse en contenedores herméticos (evitar el plástico por el aceite esencial) y protegidos de la luz y de la humedad.

\section{Órganos oficinales}

\section{Sumidad florida}

Características morfológicas de los órganos oficinales. El involucro está formado por brácteas lineares dispuestas en varias filas; las externas son de color verde con abundantes glándulas en la mitad superior y tricomas tectores, unos largos, en los márgenes de la mitad inferior, y otros más cortos, en el dorso; las medianas presentan glándulas, más abundantes en el $1 \backslash 4$ superior y tricomas tectores en los $3 \backslash 4$ inferiores; las internas son escariosas, barbudas en la cima, con tricomas tectores en los bordes y en el dorso. El receptáculo está desprovisto de brácteas interflorales. Las flores son todas tubulosas y de color amarillo, con algunas glándulas en la parte superior. Las cipselas son de color marrón, híspidas y glandulosas en la parte apical. Los pelos del vilano están dispuestos en dos filas, la externa de pelos cortos y lisos, la interna de pelos muy largos y denticulados.

Las hojas son de color verde a marrónrojizo, lanceoladas, agudas, enteras, sésiles, 

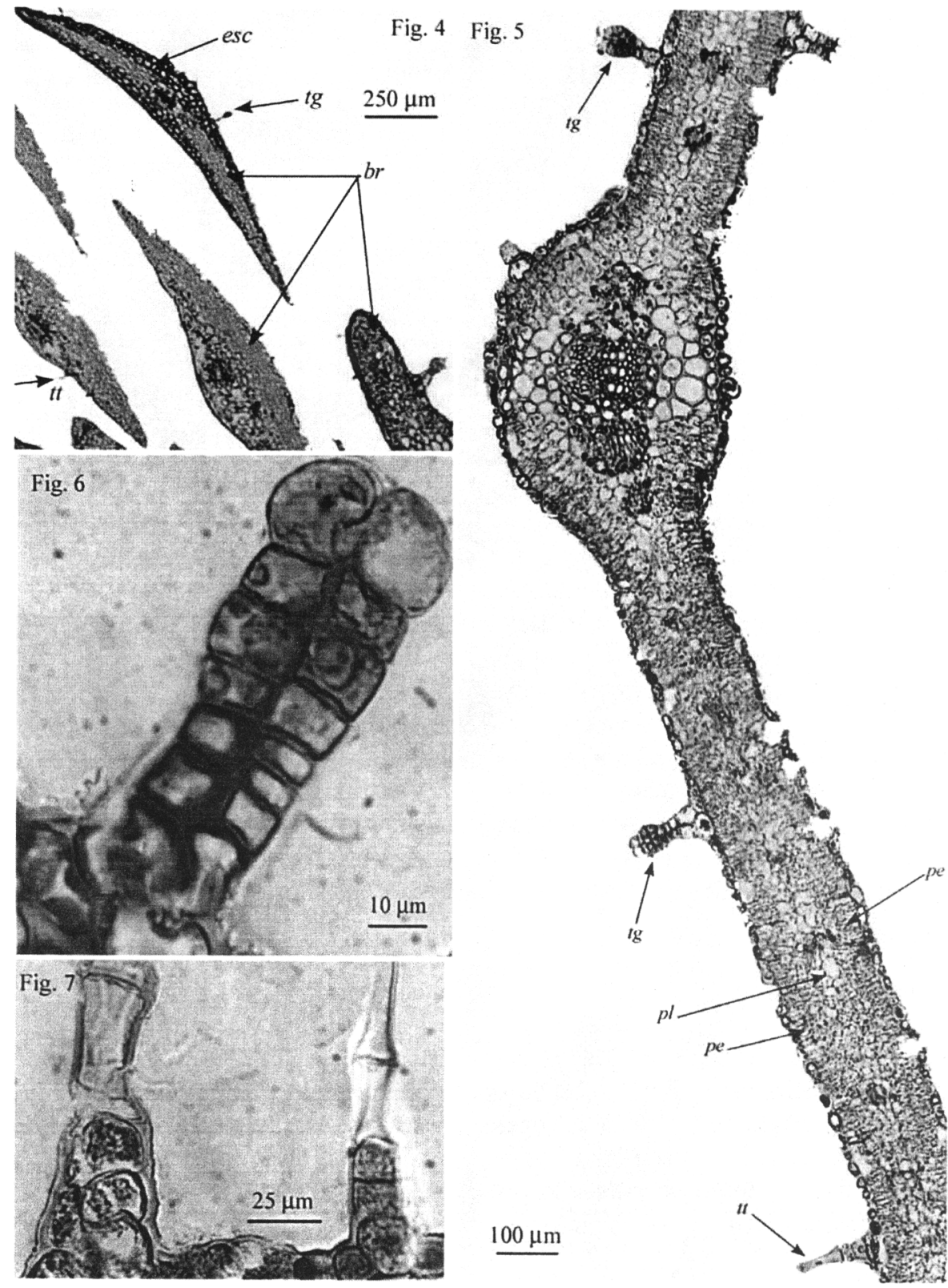

Figuras 4 a 7 . Fig. 4: Corte transversal de las brácteas del involucro. Involucral bracts in sectional view. Fig. 5; Corte transversal de la hoja. Leaf in sectional view. Fig. 6: Tricoma glandular biseriado de la hoja. Leaf's biseriate glandular trichome. Fig. 7: Tricomas tectores pluricelulares uniseriados de la hoja con las células basales diferenciadas: $b r$, brácteas; esc, esclerénquima pluriestratificado; pe, parénquima en empalizada; $p l$, parénquima lagunar; $t g$, tricomas glandulares biseriados; $t$, tricomas tectores pluricelulares uniseriados. Leaf's pluricelular, uniseriate covering trichomes with developed basal cells: br, bract; esc, pluriseriate sclerenchyma; pe, palisade parenchyma; pl, spongy parenchyma; tg, biseriate glandular trichomes; $t$, uniseriate pluricelular covering trichomes. 
atenuadas en los dos extremos y con el nervio central muy marcado en ambas caras; están cubiertas de glándulas pediceladas y de tricomas tectores.

El tallo es de color marrón-rojizo, cubierto de glándulas pediceladas y de tricomas tectores muy largos y delgados (fig. 3).

Características organolépticas de los órganos oficinales. Las hojas son muy aromáticas, de olor canforáceo y sabor un poco amargo.

\section{Características anatómico-microscó-} picas de los órganos oficinales. En un corte del capítulo se observan las brácteas del involucro con esclerénquima pluriestratificado, más abundante en las internas (fig. 4).

El mesófilo de las hojas presenta parénquima en empalizada en ambas superficies y el parénquima lagunar en la zona central. Se distinguen tricomas glandulares y tectores en ambas caras (fig. 5).

En el tallo (fig. 8) destaca la endodermis formada por células regulares y esclerénquima ectofloemático muy desarrollado.

Los tricomas glandulares (fig. 6) son pluricelulares biseriados; los tricomas tectores de las hojas y del tallo son pluricelulares uniseriados, con las células basales diferenciadas (fig. 7); los de las brácteas, son la mayor parte unicelulares y algunos bicelulares; los de la cipsela son geminados (fig. 9).

Composición química. Aceite esencial. Principios amargos como lactonas sesquiterpénicas; taninos y heterósidos (Arteche et al. 1998).

Acción farmacológica. Se le atribuyen propiedades aperitivas, espasmolíticas, digestivas, antidiarréicas, anticatarrales e hipotensoras. En aplicación tópica se considera hemostática, antiséptica, antifúngica y antiinflamatoria (Arteche et al. 1998, Stübing et al., 1998).

Estudios in vitro, muestran que el extracto cetónico puro posee actividad contra Leishmania donovani y Entamoeba histolytica (Villaescusa et al. 1996).

Indicaciones. Se emplea principalmente en trastornos digestivos (dispepsias hiposecretoras, flatulencia, espasmos gastrointestinales) e inapetencia. También como anticatarral y antidepresivo. En uso externo en heridas, contusiones, eczemas, blefaroconjuntivitis, dermatomicosis, faringitis, vulvovaginitis, craurosis vulvovaginal (Arteche et al. l.c., Villaescusa et al., l.c.).

Se trata de una planta poco estudiada y su eficacia no está comprobada.

Precauciones/Intoxicación. A dosis elevadas puede producir efectos eméticos. Popularmente se la considera abortiva. Está contraindicada durante el embarazo (Arteche et al. l.c., Gómez 1999).

Adulteraciones y sustituciones. Se puede confundir con Jasonia tuberosa (L.) DC. (té de burro, té de glera, o té de tierra) que se diferencia de J. glutinosa (L.) DC., por tener las hojas obtusas, generalmente flores liguladas en la periferia y la cipsela sin glándulas en la parte superior.

Formulación. J. glutinosa (L.) DC. se utiliza en infusión sustituyendo al té común (sobre todo en Cataluña y Aragón) y también en algunas preparaciones compuestas para el control de peso. Ejemplo: Fucus vesiculosus L., 30\% (estimulante tiroideo, saciante, diurético); Equisetum arvense L. $20 \%$ (diurético, remineralizante); Smilax officinalis Griseb. 20\% (diurético); Jasonia glutinosa (L.) DC. $20 \%$ (digestiva); Mentha piperita L. $10 \%$ (digestiva, colagoga, colerética, carminativa) 

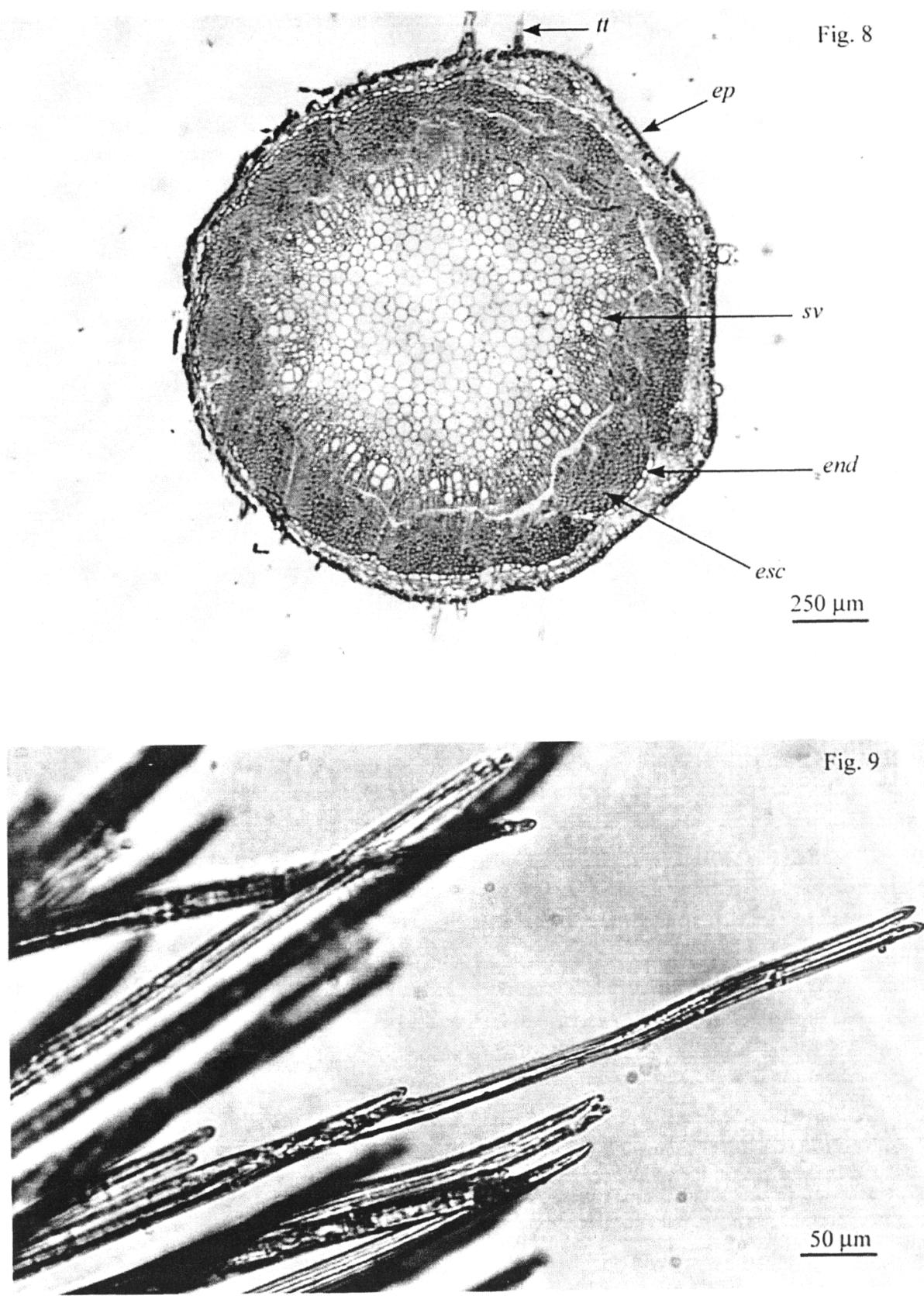

Figuras 8 y 9. Fig. 8: Corte transversal del tallo. Part of the steam in sectional view. Fig. 9: Tricomas tectores geminados de las cipselas: end, endodermis; ep, epidermis; esc, esclerénquima; pm, parénquima medular; $s v$, sistema vascular; $t$, tricomas tectores. Achenes' geminate covering trichomes: end, endodermis; ep, epidermis; esc, sclerenchyma; $p m$, parenchyma of the pith; $s v$, vascular system; $t$, covering trichomes. 


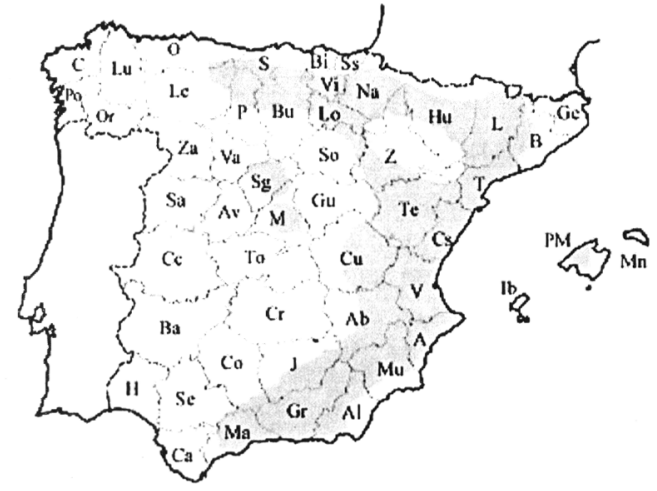

Figura 10. Distribución de Jasonia glutinosa (L.) DC. en la Península Ibérica y Baleares (Bolós et al. l.c.). Jasonia glutinosa (L.) DC. distribution in the Iberian Peninsula and Baleares Isles (Bolós et al. l.c.).

(Registro especial de plantas medicinales $\mathrm{N}^{\circ}$ PM-1775).

\section{BIBLIOGRAFÍA}

ARTECHE, A., J.A. FERNANDEZ, J.I. GÜENECHEA y B. VANACLOTXA -1998Fitoterapia. Vademecum de prescripción. CITAPE. S.L., Barcelona.

BOLÓS, O. y J. VIGO -1995- Flora dels Països Catalans. Tomo III. Barcino. Barcelona.

COSTE, H. -1937- Flore Descriptive et Ilustrée de la France. Tomo II. Librairie Scientifique et Technique. Paris.

FAHN, A -1985-Anatomía Vegetal. Ed. Pirámide, S.A. Madrid.

FIORI, A., \& G. PAOLETTI -1970- Iconographia florae italicae. Flora italiana illustrata. Edagricole. Bologna.

FONT QUER, P. -1978- Plantas medicinales. El Dioscórides renovado. Labor. Barcelona.

FONT QUER, P. -1993-Diccionario de Botánica. Tomos II-III. Labor S.A. Barcelona.

GÓMEZ, D. -1999- Las plantas de extractos. Bases para un Plan de Desarrollo del Sector. Fundación Alfonso Martín Escudero. Melissa, S.A. Madrid.
PAMPLONA, J. -1999-Enciclopedia de las plantas medicinales. Tomos. I-II. Safeliz. Madrid.

PARIS, R. R. \& H. MOYSE-1971-Precis de Metière Médicale. Tomo III. Masson et Cie., Editeurs. Paris.

STÜBING G. y J.B. PERIS -1998- Plantas medicinales de la Comunidad Valenciana. Valencia: Generalitat Valenciana. Conselleria de Medio Ambiente. Valencia.

TOLIVIA, D. \& J. TOLIVIA -1987- Fasga. A new polychromatic method for simultaneous and differential staining of plant tissues. Journal of Microscopy 148: 113-117.

TUTIN, T.G., V.H. HEYWOOD, N.A. BURGES, D.M. MOORE, D.H. VALENTINE, S.M. WALTERS \& D.A.WEBB -1972- Flora europaea. Tomo IV. Univ Press. Cambridge.

VALDÉS, B., S. TALAVERA y E. FERNÁNDEZ GALIANO - 1987- Flora vascular de Andalucía occidental. Tomo III. Ketres. Barcelona.

VILLAESCUSA, L., A.M. DIAZ, T. MARTIN, M. GASQUET, F. DELMAS \& G. BALANSARD 1996-. Preliminary screening of antiprotozoal activity of Jasonia glutinosa aerial parts. En: Int-J-Pharmacogn, 1996, v. 34, n. 4, pp. 303304.

Aceptado para su publicación en julio de 2003

Dirección de la autora.Dpto. Botánica. Avda. Ldo. Méndez Nieto, s/n. Fac. Farmacia. Univ, de Salamanca. 37007 - SALAMANCA 